\title{
The holy trinity of Canadian health policy
}

\author{
Exploring Social Insurance: Can a Dose of \\ Europe Cure Canadian Health Care Finance? \\ Colleen M. Flood, Mark Stabile and \\ Carolyn Hughes Tuohy, Eds. \\ McGill-Queen's University Press; 2008. \\ 290 pp $\$ 34.95$
}

B etter health care. No queue jumping. And lower taxes. Most Canadians favour all 3 parts of this holy trinity. Is it possible that injecting a dose of Europe into the Canadian health care system might allow all 3 goals to be realized? Could social insurance be the financing mechanism of choice in an era when health care spending is likely to continue to increase at a faster rate than government revenue?

Not everybody uses the term social insurance the same way, but most experts define 2 essential features: individuals are required to make regular, incomedependent payments and these contributions are managed by quasi-independent, non-profit insurers. Insurers may compete with one another, or there may be geographic or employment-based monopolies. The advantages and disadvantages of these essential features are explored in detail in this timely volume, with key contributions from Stefan Greß, Wynand van de Ven, Ted Marmor, Steve Morgan, Terry Sullivan and the editors.

Greß and colleagues use the German example to demonstrate that although social insurance has the potential to be as equitable as taxation it tends to result in a greater financial burden being placed on the working poor.

Van de Ven and colleagues highlight the main problem introduced by competition: the desire to shy away from insuring the ill, because their costs exceed their contributions. They also point out that the potential benefit of competition - improved efficiency — has been largely unrealized in social insurance systems.

Marmor starts by warning us that international comparative studies can be misleading before concluding that social insurance in Canada might be a "policy option for expanding the bases of politi-

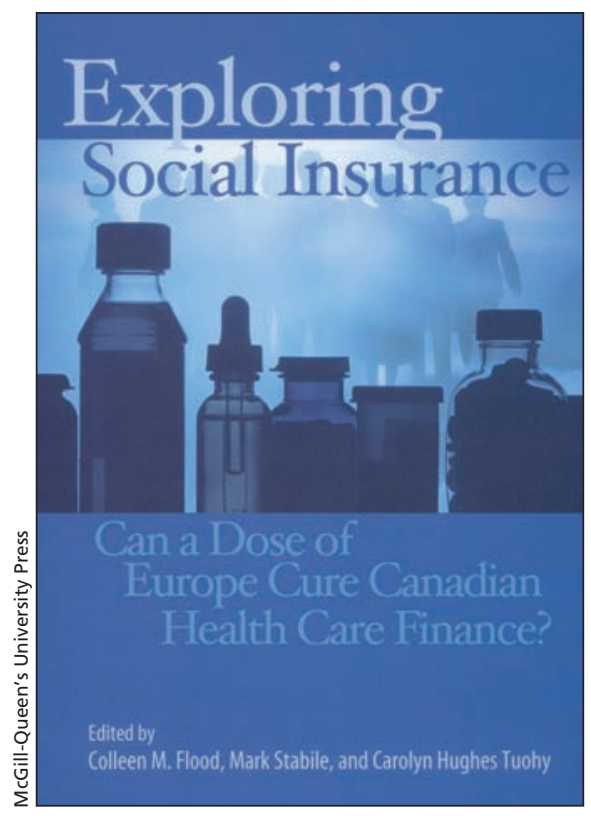

cal support rather than a source of fiscal magic." A useful insight.

On the pharmaceutical front, Morgan provides a comprehensive overview of Canada's pharma financing before discussing whether social insurance might represent a way forward. $\mathrm{He}$ astutely notes that it would be "unwise to create a pharmaceutical insurance system that simply aims to cover the costs of drug purchases" without "setting and managing reasonable limits for [the] pooled funds."

The book might have benefited from the perspective of a physician practising in a country with social insurance given that the manifestations of health-system dysfunction vary by country: Canadians endure waiting lists, a doctor shortage and inequitable access to prescription medications. Americans bemoan a lack of universal coverage, exorbitant patient charges and a vast insurance bureaucracy. What do the French, Germans and Dutch put up with? Advocates suggest these systems function well, yet all 3 have reformed their financing mechanisms in the last few years. A few of the contributors offer some macro-level answers (e.g., a shrinking employment base has eroded social insurance revenues), but I wondered whether a practising physician might have been able to provide some useful insights.

The editors' most enduring contribution in this volume is in the final chapter, where they present a practical proposal for a comprehensive, universal pharmacare program. They explicitly recognize that a pharmacare plan funded through social insurance might not be as equitable as a tax-based plan, but, because "social insurance contributions dedicated to health care could be more attractive [to voters] than increases in general taxation," they argue that diversifying the funding base might lead to more money being available for health care.

In other words, all 3 aspects of the holy trinity might be achievable - providing, of course, that voters and politicians discriminate between social insurance contributions and taxes. In the editors' proposal, private insurers would be regulated closely, individuals and employers would be required to acquire and offer insurance respectively, and a new, arm's length body - the social insurer - would be established to manage public contributions and to purchase drugs. Because their proposal builds on the existing private insurance framework, it may be politically viable.

Anyone concerned about how Canada should pay for health care will find this book interesting, in particular those who look to Europe for solutions and those who wish to improve access to prescription drugs. The first group may be slightly disappointed by what it finds, for Europe offers no easy answers. The second group, however, will find succour. And if enough people agree with Professors Flood, Stabile and Tuohy, social insurance might end up being the way that Canada belatedly achieves pharmacare.

\section{Irfan Dhalla MD MSc \\ Lecturer \\ Department of Medicine \\ University of Toronto \\ Toronto, Ont.}

This book's foreword, by Hugh Segal, is available online at www.cmaj.ca/cgi /content/full/180/2/211/DC1 